\title{
Foreword: Why the Space of the Latinx Speculative Matters
}

\section{FREDERICK LUIS ALDAMA}

I love my sci-fi. As a teen, I gorged on all that our local librarian recommended: from Mary Shelly, Ursula K. Le Guin, Octavia Butler, Issac Asimov, and Frank Herbert to Julio Cortázar and Jorge Luis Borges. While over the years I would return to these authors whenever given the chance, today I find myself more and more drawn to the speculative in comic books, television shows, and films. This does not in any way reflect a hierarchy of quality: word-drawing narrative, say, as better than alphabetic narrative. It's simply a question of time. I usually have a few minutes to spare and some energy left at day's end, giving these minutes over to imaginative indulgences in speculative spaces built by comics, television shows, and films. What hasn't changed from my teens to today is the dominant impulse. I go to sci-fi less for the plots and more for the exciting ways that creators build new worlds. I'm fascinated by how different creators extrapolate, reimagine, and reconstruct the building blocks of my everyday reality. I'm especially fascinated by how these newly built storyworlds reconstruct the planet's Brown folx.

Mainstream sci-fi (all media and modes) has a deleterious track record when it comes to imagining our historically underrepresented communities of color: Latinx, African American, Asian American, and Indigenous people. Dip into any moment in the mainstream's deep planetary time and reconstructions of folx of color (when they do happen) and they nearly always appear as sets of 
binary opposites: as exoticized and sexualized Others a la Pocahontas or as untrustworthy, villainous Others.

I recall here a few emblematic examples of mainstream reel sci-fi's lazy and damaging reconstructions of Latinxs. Barry Sonnenfeld's Men in Black (1997) includes as its precredit launch into the story proper the following scene: on the U.S. side of the Mexico/U.S. border, a racist migra stops a coyote who is transporting undocumented Latinxs. Agent K (Tommy Lee Jones) and Agent $\mathrm{D}$ (Richard Hamilton) save the undocumented Latinxs, telling them to continue on their way. They hold back one of the border crossers, however-the poncho-wearing Latinx (Sergio Calderón) who doesn't understand Agent K's Spanish. This undocumented Latinx is sliced open from head to toe, revealing an amphibious, flippered alien named Mikey, who, as it turns out, recently escaped prison. These first few minutes of the film reveal much about how Latinxs are reconstructed. There's the Anglo beneficent paternalism: Agent K's generous gesture to let the undocumented Latinxs go free. There's the Latinx threat narrative: the Latinx as literal alien who stealthily crosses into the United States to cause trouble.

Then we have those sci-fi reel reconstructions of Latinxs that identify the geographic region of Mexico as monstrous. In David Twohy's The Arrival (1996) and Ed Gareth Monsters (2010), Mexico becomes the home base for space aliens to take over the United States and the planet. In the former, some aliens disguise themselves as gardeners (yes, gardeners) to infiltrate the United States. In the latter, the Godzilla-sized space aliens are contained in Mexico by a giant wall.

When sci-fi reels don't mark Latinxs as alien and threatening, they spin narratives of Latinxs as easy disposables, usually to intensify the audiences' empathy for and appreciation of the Anglo protagonist. I think here of Anna (Elpidia Carrillo) as the disposable Latina in Predators (1997) who functions to focus attention on the deft, hunter skills of Dutch (Arnold Schwarzenegger). I think here also of Anya Thorensen (Gina Rodriguez) as the disposable Latina in Alex Garland's Annibilation (2018), who exists only to ultimately intensify audience emotion for Anglo cellular biologist Lena (Natalie Portman).

When mainstream sci-fi reels reconstruct Latinxs as safe (alien or otherwise), their roles are usually woven thickly within those age-old stereotypes of the exotic and noble savage Other. Think Zoe Saldana's roles in the Guardians of the Galaxy (2014) and Avatar (2009). Her Latinidad is contained and made safe through her hyperexoticization, through makeup (green or purple) and scripts that replay the non-White characters as primitive, naive, and in need of a White savior.

It's not all doom and gloom, of course. The recent spate of Star Wars films has featured some notable exceptions. In Rogue One (2016), Diego Luna infuses 
complexity and depth to the role of Cassian Andor-and Luna's insistence that he play the role with his Mexican-accented English adds to this complexity. And in the recent Star Wars trilogy (2015-2019), Guatemalan-born Latinx actor Oscar Isaac as Poe softens the machista attitude of the Latinx warrior figure with his infusion of a nuanced and affectionate interracial, male-male (John Boyega as Finn) relationship. Disney+ channel's casting of Pedro Pascal as the eponymous hero of its The Mandalorian has cleared new spaces for seeing (actually, hearing, as he's only unmasked near the end of Season I) complex articulations of Latinx masculinities: that one can be a warrior and a loving single parent to a nonbiologically related child; in this case, the child popularly identified by Latinxs in the social media sphere as Yodito.

In television, we're seeing some excellent, even radical, sci-fi reel reconstructions of Latinxs. I think readily of such sci-fi shows as SyFy's Caprica (2010), HBO's Westworld (2017-), and CBS's Star Trek: Discovery (2017-). Caprica gives most screen time to developing the complex Adama family (with Esai Morales as Joseph Adama) as ethnoracially persecuted Taurons; the show is set in the future and on other planets, but in a way that serves as a smart allegory to the race relations in our tellurian present. Westworld features as one of its central robot protagonists the leader of the robot revolution: gunslinger Hector Escatón (Rodrigo Santoro), who wakes to his exploitation and oppression to rise up against the human world. And Star Trek: Discovery gives remarkable amounts of screen time to developing the smart and queer Dr. Hugh Culber (Wilson Cruz).

Of course, the real reel innovations in sci-fi storyworld building are happening with Latinxs behind cameras, pencils, pens, and typewriters. There's the notably sophisticated, politically nuanced transfrontera cross-border sci-fi films and installation art of Alex Rivera that includes Sleep Dealer (2009) as well as Memorial over General Atomics and Lowdrone. There are the genre-bending, epic-scaled sci-fi narratives of Robert Rodriguez, including Planet Terror (2007), Machete Kills (2013), Red II (2019), and Alita: Battle Angel (2019). Rivera and Rodriguez build complex sci-fi storyworlds that reconstruct all facets of today's Latinx life and culture-and that imagine new ways that our culture will be as it grows across the Américas. Both directors invite-in fact, urgeaudiences to imagine the ways we can actively transform this tomorrow for the better and more humane.

With pencil and ink, Latinx creators of comics have been revolutionizing sci-fi narrative spaces-and with head-spinning abundance. With Rocketo (2006), Frank Espinosa reconstructs his own Cuban émigré experience in a future where the world is nearly all water, with a few island territories known only to the Mapper, Rocketo. Also taking place on a radically transformed planet, Los Bros Gonzalez (John and Carlos) and Julian Aguilera's multiethnic superhero team speak truth to ecological disaster in The Elites (2014-). The 
adventures and epic battles that energize Jules Rivera's Valkyrie Squadron (2018) importantly grow and empower a radical decolonial politics. With God and Science: Return of the Ti-Girls (20I2), Jaime Hernandez creates a near all-women storyworld, including Latina Penny Century, Espectra, Weeper, Cheetah Torpeda, and Space Queen. In Jaime's speculative comic book space, there's no room for patriarchal familial systems; when there are infants, they're tucked away in belt buckles so the Latinas can kick some culo. In my forthcoming Labyrinths Borne (with Juan Argil), I imagine a future after The Event where all but the teenagers have perished; we build a storyworld space that imagines the vital creative, intellectual energy of teens, including the protagonist, Luna, who turn to science, philosophy, and literature as a way to positively transform the planet.

Many Latinx comics creators choose to build storyworlds that reconstruct the past, and with this decolonize history textbooks that erase the significant presence of transformative Latinx subjects in deep planetary time and place. Rafael Navarro and Mike Wellman's Guns A'Blazin'! rewrites yesteryear's Anglocentric Manifesto destiny narratives by featuring the Latinx Eduardo as a supped-up-roadster time traveling cowboy. And we go back even deeper into planetary time with Daniel Parada's precolonial set superhero adventure, Zotz: Serpent and Shield (201-).

Of course, comics are not the only generative space for the speculative reconstructions of Latinx experiences and subjectivities. There is also the vital and transformative work happening within children's and young adult fictional spaces. For instance, I wanted to create a story that touched on today's caging of Latinx children along the U.S./Mexico border. I wanted it to be an adventure story, however, that drew on the powerfully speculative oral stories Latinxs have heard growing up in the Southwest and Puerto Rico: the myth of the Chupacabra, the goat sucker. Working with illustrator Chris Escobar, I created The Adventures of Chupacabra Charlie (2020), which follows the adventures of a learned, vegetarian, adventure-seeking Chupacabra named Charlie. And we're seeing a tremendous outpouring of vital Latinx storyworld building in the YA fictional realm. I think of Daniel José Older and Zoraida Córdova who are radically infusing a Latinx sensibility into their re-creations of Star Wars narratives such as Last Shot: A Han and Lando Novel (2018) and Star Wars: Galaxy's Edge: A Crash of Fate (2019), for instance. I also think of Malka OlderInfomocracy (2016), Null States (2017), and State Tectonics (2018) — who builds pre-Colombian mythologically informed storyworlds that critique our current epidemics of destructive social and political behavior, and affirm new intersectional identities and transformative spaces.

Goodwin's book provides us with the concepts and vocabulary to understand better what we might otherwise only intuitively grasp. This book also 
forcefully reminds us that as we face a reality that seems increasingly unbearable—climate change, border patrolling, children caged, families ripped apart-Latinx sci-fi urgently matters. It's this space of the Latinx speculative that will open eyes to other ways of imagining and seeing a tomorrow where all of the planet's organic life-forms can discover, create, and thrive in stunning new ways. 
